\title{
Article
}

\section{Bound Polyphenols from Red Quinoa Prevailed over Free Polyphenols in Reducing Postprandial Blood Glucose Rises by Inhibiting $\alpha$-Glucosidase Activity and Starch Digestion}

\author{
Yu Zhang ${ }^{1,2}$, Bing Bai ${ }^{1}$, Yu Yan ${ }^{1}$, Juan Liang ${ }^{1}$ and Xiao Guan ${ }^{1,2, *}$ \\ 1 School of Health Science and Engineering, University of Shanghai for Science and Technology, \\ Shanghai 200093, China; zyu20@usst.edu.cn (Y.Z.); Baibing0714@126.com (B.B.); yanyu981622@163.com (Y.Y.); \\ nxlj5200@163.com (J.L.) \\ 2 National Grain Industry (Urban Grain and Oil Security) Technology Innovation Center, \\ Shanghai 200093, China \\ * Correspondence: gnxo@163.com
}

check for updates

Citation: Zhang, Y.; Bai, B.; Yan, Y.;

Liang, J.; Guan, X. Bound

Polyphenols from Red Quinoa

Prevailed over Free Polyphenols in

Reducing Postprandial Blood

Glucose Rises by Inhibiting

$\alpha$-Glucosidase Activity and Starch

Digestion. Nutrients 2022, 14, 728.

https://doi.org/10.3390/nu14040728

Academic Editor: Emad Al-Dujaili

Received: 10 January 2022

Accepted: 4 February 2022

Published: 9 February 2022

Publisher's Note: MDPI stays neutral with regard to jurisdictional claims in published maps and institutional affiliations.

Copyright: (C) 2022 by the authors. Licensee MDPI, Basel, Switzerland. This article is an open access article distributed under the terms and conditions of the Creative Commons Attribution (CC BY) license (https:// creativecommons.org/licenses/by/ $4.0 /)$.

\begin{abstract}
Inhibiting $\alpha$-glucosidase activity is important in controlling postprandial hyperglycemia and, thus, helping to manage type-2 diabetes mellitus (T2DM). In the present study, free polyphenols (FPE) and bound polyphenols (BPE) were extracted from red quinoa and their inhibitory effects on $\alpha$-glucosidase and postprandial glucose, as well as related mechanisms, were investigated. HPLC-MS analysis showed that the components of FPE and BPE were different. FPE was mainly composed of hydroxybenzoic acid and its derivatives, while BPE was mainly composed of ferulic acid and its derivatives. BPE exhibited stronger DPPH and ABTS antioxidant activities, and had a lower IC50 $(10.295 \mathrm{mg} / \mathrm{mL})$ value in inhibiting $\alpha$-glucosidase activity. The inhibition kinetic mode analysis revealed that FPE and BPE inhibited $\alpha$-glucosidase in a non-competitive mode and an uncompetitive mode, respectively. Furthermore, compared to FPE, BPE delayed starch digestion more effectively. $\mathrm{BPE}$ at $50 \mathrm{mg} / \mathrm{kg}$ reduced postprandial glucose increases comparably to acarbose at $20 \mathrm{mg} / \mathrm{kg}$ in ICR mice. These results could provide perspectives on the potential of BPE from red quinoa, as a functional food, to inhibit $\alpha$-glucosidase activity, delay postprandial glucose increases and manage T2DM.
\end{abstract}

Keywords: bound polyphenols; quinoa; $\alpha$-glucosidase; T2DM; postprandial glucose

\section{Introduction}

According to the World Health Organization, the number of people with diabetes rose from 108 million in 1980 to 422 million in 2014. In 2019, an estimated 1.5 million deaths were directly caused by diabetes [1]. Type-2 diabetes mellitus (T2DM) makes up about $90 \%$ of cases of diabetes. Glycemic control is considered as an effective way to manage T2DM, and prolonged carbohydrate digestion is beneficial for T2DM patients. $\alpha-$ glucosidase secreted in the small intestine catalyzes the end phase of disaccharides digestion to monosaccharides. Thus, inhibiting $\alpha$-glucosidase activity serves as an effective strategy in delaying the digestion of carbohydrate in the gut and reducing the postprandial blood glucose peak [2]. Some clinical drugs aimed at inhibiting the activity of $\alpha$-glucosidase have been invented, such as acarbose, miglitol and voglibose. However, long-term use of clinical $\alpha$-glucosidase inhibitors often causes some side effects, such as abdominal discomfort and flatulence [3]. Thus, natural food-derived substances with $\alpha$-glucosidase inhibitory activity show superiority over some clinical drugs due to their safety and reduced risks of side effects.

Polyphenols, as a major subcategory of phytochemicals, constitute an indispensable part of our daily diet. Polyphenols from various sources, such as tea [4], berries [2] and cereal grains [5], have been reported to show $\alpha$-glucosidase inhibitory activity and, thus, reduce glucose absorption in the gut. However, most of the studies merely focus on the 
free polyphenols that are directly extracted from organic solvents. A large part of nonextractable bound polyphenols is ignored, which leads to an underestimation of the total polyphenols content and nutritional value of foods. Bound polyphenols are bound to cell wall components, such as dietary fibers, via chemically covalent bonds, hydrogen bonding and hydrophobic interactions [6]. After solvent extraction, bound polyphenols can be extracted from the remaining solid residues through alkaline/acidic/enzymatic hydrolysis. Cereal grains are important sources of dietary polyphenols, and studies reported that the proportion of bound polyphenols in cereal grains $(\sim 60 \%)$ was higher than those in fruits and vegetables $(\sim 24 \%)$ [7].

Quinoa (Chenopodium quinoa Willd.), native to the Andean regions of Chile, Peru and Bolivia, is considered as "golden grain" by local people. The high nutritional value of quinoa, including its ideal protein profile, and rich contents of vitamins and polyphenols, brings many health benefits, such as antioxidant, anti-diabetic and anti-obesogenic activities [8]. It was previously shown that pigmented cereal grains contained higher content of polyphenols than non-pigmented ones [9]. Although previous studies have reported the enzyme-inhibitory activities of quinoa polyphenols, there are still a lack of data pertaining to the comparison of free polyphenols and bound polyphenols from red quinoa in the inhibitory effects and mechanism of $\alpha$-glucosidase, and their effects on starch digestion in vitro and postprandial glucose in vivo. The present study obtained free polyphenols extract (FPE) and bound polyphenols extract (BPE) from red quinoa, and analyzed their composition via HPLC-MS. Their antioxidant activities, effects on $\alpha$-glucosidase and related mechanism, and effects on starch digestion were investigated in vitro. Furthermore, the postprandial glucose level and Area Under the Curve (AUC) of mice administrated with FPE and BPE were investigated in vivo. Our results aimed to provide a theoretical reference for the development of functional foods for T2DM, and expand the application of quinoa-related components.

\section{Methods and Materials}

\subsection{Reagents and Materials}

Red quinoa grains were purchased from Yihe Agricultural Products Sales Co., Ltd. (Fanshi, Shanxi Province, China). Methanol and acetonitrile for HPLC analysis were of HPLC grade. 2,2-diphenyl-1-picrylhydrazyl (DPPH), 2,2'-azino-bis-(3-ethylbenzo-thiazoline6-sulphonic acid) diammonium salt (ABTS), $\alpha$-glucosidase and maltose were purchased from Sigma-Aldrich (St. Louis, MO, USA). All other chemicals were of analytical grade.

\subsection{Extraction of FPE and BPE}

The extraction of free polyphenols and bound polyphenols from red quinoa grains was conducted according to previous studies with slight modification [10]. Briefly, red quinoa grains $(40 \mathrm{~g})$ were ground into powder and extracted with $70 \%$ ethanol $(1 \mathrm{~L})$. The extraction was carried out on a rotary shaker at $400 \mathrm{rpm}$ for $3 \mathrm{~h}$ at room temperature. The mixture was centrifuged at $6000 \mathrm{rpm}$ for $10 \mathrm{~min}$ (Thermo Fisher Scientific, Waltham, MA, USA) and the supernatant solution was collected and rotary-evaporated under vacuum. Dichloromethane was then added for liquid-liquid extraction to remove the hydrophobic components from the red quinoa grains. The dichloromethane layer was removed and the organic solvent was rotary-evaporated under vacuum. The solution was lyophilized into dryness and labelled as free polyphenols extract (FPE). Then, the residue $(20 \mathrm{~g})$ was first treated with $250 \mathrm{~mL}$ of $2 \mathrm{M} \mathrm{NaOH}$ for a 4-h hydrolysis at room temperature. The mixture was acidified to $\mathrm{pH} 2$ with $6 \mathrm{M} \mathrm{HCl}$, and then centrifuged at $6000 \mathrm{rpm}$ for $10 \mathrm{~min}$. The supernatant was collected and the extraction process of bound polyphenols extract (BPE) was similar to that of FPE as described above.

\subsection{Detection of Total Polyphenols Content and Total Flavonoids Content}

The total polyphenols content (TPC) was determined using the Folin-Ciocalteu assay. Briefly, $400 \mu \mathrm{L}$ of sample solution (FPE or BPE dissolved in distilled water) was added to 
$1 \mathrm{~mL}$ of $1 \mathrm{M}$ Folin-Ciocalteu reagent. The mixture solution was diluted to $2 \mathrm{~mL}$ and was shaken thoroughly. The mixture solution was kept in darkness for $5 \mathrm{~min}$ at room temperature. A quantity of $5 \mathrm{~mL}$ of $5 \% \mathrm{Na}_{2} \mathrm{CO}_{3}(w / v)$ was added to the mixture solution and the reaction was maintained for $60 \mathrm{~min}$ at room temperature. Later, the absorbance was read at $765 \mathrm{~nm}$. Results were expressed at milligrams per gram of gallic acid equivalents (GAE).

The total flavonoids content (TFC) was determined based on a previous method with slight modification [11]. In brief, $100 \mu \mathrm{L}$ of sample solution (FPE or BPE dissolved in methanol) was mixed completely with $300 \mu \mathrm{L}$ of $5 \% \mathrm{NaNO}_{2}$ and stood for $5 \mathrm{~min}$. Then, $300 \mu \mathrm{L}$ of $10 \% \mathrm{Al}\left(\mathrm{NO}_{3}\right)_{3}$ was added to the mixture and stood for $6 \mathrm{~min}$. A quantity of $4 \mathrm{~mL}$ of $1 \mathrm{M} \mathrm{NaOH}$ was added afterwards and $400 \mu \mathrm{L}$ of $30 \%$ ethanol was added to make a final volume of $10 \mathrm{~mL}$. The mixture was completely vortexed and stood for $10 \mathrm{~min}$. The absorbance was measured at $510 \mathrm{~nm}$. The TFC was expressed as milligrams per gram of rutin equivalent (RE).

\subsection{Liquid Chromatography Analysis of FPE and BPE}

UPLC-UV-ESIMS analysis was performed on a Waters Acquity I-Class platform coupled with a Bruker Esquire 3000 Plus ion trap mass spectrometer (Bruker-Franzen Analytik $\mathrm{GmbH}$, Bremen, Germany). Mass Spectra were achieved by electrospray ionization (negative mode). A Zorbax SB-C18 (Agilent, Santa Clara, CA, USA) column $(250 \times 4.6 \mathrm{~mm}$, $5 \mu \mathrm{m}$ ) was used for separation. The mobile phase consisted of (A) $0.1 \%$ formic acid solution and (B) $95 \%$ methanol and 5\% acetonitrile. The flow rate was $0.8 \mathrm{~mL} / \mathrm{min}$ and the column temperature was kept at $45{ }^{\circ} \mathrm{C}$. The elution program was as follows: $0-40 \mathrm{~min}, 0-80 \% \mathrm{~B}$; 40-42 $\mathrm{min}, 80-100 \% \mathrm{~B} ; 42-44 \mathrm{~min}, 100 \% \mathrm{~B} ; 44-50 \mathrm{~min}, 100-0 \% \mathrm{~B}$. The injection volume was $10 \mu \mathrm{L}$ and the UV detection wavelengths were set at $280 \mathrm{~nm}$. Commercial standards were used for the quantification of specific polyphenols of FPE and BPE.

\subsection{DPPH and ABTS Assays}

The DPPH assay was performed as previously reported [12]. In brief, $100 \mu \mathrm{L}$ of sample solution (FPE or BPE dissolved in ethanol) was added into $3.9 \mathrm{~mL}$ of $0.1 \mathrm{mM}$ DPPH in ethanol. The mixture was kept in darkness for $20 \mathrm{~min}$ at room temperature. Afterwards, the absorbance was measured at $517 \mathrm{~nm}$. Results were expressed as milligrams per gram of Trolox equivalents (TE).

The ABTS assay was performed as previously reported [12]. Quantities of $25 \mathrm{~mL}$ of $7 \mathrm{mM}$ ABTS solution and $440 \mu \mathrm{L}$ of $140 \mathrm{mM}$ potassium persulfate solution were mixed to form the ABTS+ cation solution, which was kept in darkness for 12-16 h before use at room temperature. The ABTS+ cation solution was diluted with ethanol until its absorbance value was $0.7 \pm 0.02$ at $734 \mathrm{~nm}$. Then, $100 \mu \mathrm{L}$ of sample solution (FPE or BPE dissolved in ethanol) was added to the diluted ABTS+ cation solution $(3.9 \mathrm{~mL})$. The mixture was kept in darkness for10 min at room temperature. The absorbance was read at $734 \mathrm{~nm}$ and the results were expressed as milligrams per gram of TE.

\section{6. $\alpha$-Glucosidase Inhibition Assay and Inhibition Kinetic Mode}

The inhibitory effects of FPE and BPE were assessed based on previous studies with slight modification [13,14]. A quantity of $25 \mu \mathrm{L}$ of sample solution was mixed with $25 \mu \mathrm{L}$ of $\alpha$-glucosidase $(1 \mathrm{U} / \mathrm{mL})$, and the reaction was maintained for $10 \mathrm{~min}$ at $37^{\circ} \mathrm{C}$. Then, $25 \mu \mathrm{L} 5 \mathrm{mM}$ of pNPG in $0.1 \mathrm{M}$ phosphate buffer ( $\mathrm{pH}$ 6.8) was added to the mixture and reacted for $10 \mathrm{~min}$ at $37^{\circ} \mathrm{C}$, followed by the addition of $50 \mu \mathrm{L}$ of $\mathrm{Na}_{2} \mathrm{CO}_{3}(100 \mathrm{mM})$ to stop the reaction. The absorbance was read at $450 \mathrm{~nm}$ using a micro-plate reader (BioTek Instruments, Winooski, VT, USA). All samples were measured in triplicate. The inhibition rate of FPE or BPE was calculated using Equation (1):

$$
\% \text { inhibition rate }=\frac{\left(A_{\text {control }}-A_{\text {control blank }}\right)-\left(A_{\text {sample }}-A_{\text {sample blank }}\right)}{\left(A_{\text {control }}-A_{\text {control blank }}\right)}
$$


where $A_{\text {control }}$ refers to the absorbance of the buffer with the enzyme; $A_{\text {control blank }}$ refers to the absorbance of the buffer without the enzyme; $A_{\text {sample }}$ refers to the absorbance of FPE or BPE with the enzyme; $A_{\text {sample balnk }}$ refers to the absorbance of FPE or BPE without the enzyme. The IC50 value, meaning the concentration of FPE or BPE required for $50 \%$ inhibition of $\alpha$-glucosidase activity, was used to measure the inhibitor potency.

The inhibition mode of FPE or BPE against $\alpha$-glucosidase was determined according to the plots of a double reciprocal line $(1 / v$ versus $1 / S)$ using the Lineweaver-Burk model. The concentrations of pNPG ranged from 0.5 to $5 \mathrm{mM}$, and the concentrations of FPE or BPE were $10 \mathrm{mg} / \mathrm{mL}$ and $20 \mathrm{mg} / \mathrm{mL}$. The Michaelis constant $\left(K_{m}\right)$ and maximal velocity $\left(V_{\max }\right)$ were obtained from the plots:

$$
\frac{1}{v}=\frac{1}{V_{\max }}+\frac{K_{m}}{V_{\max }} \frac{1}{[S]}
$$

where $v$ refers to the initial velocity and [S] refers to the concentration of substrate (pNPG).

\subsection{Effects of FPE and BPE on the Digestion of Starch In Vitro}

The effects of FPE and BPE on the digestion of rice starch in vitro were tested based on a previous study with slight modification [13]. Rice starch solution ( $2 \%$ in acetate buffer, $\mathrm{pH}$ 5.2) with FPE or BPE $(10 \mathrm{mg} / \mathrm{mL})$ was prepared. The mixture was heated at $90{ }^{\circ} \mathrm{C}$ to gelatinize for $20 \mathrm{~min}$. The simulated process of starch digestion was started by adding $3 \mathrm{~mL}$ of mixed enzymes solution ( $\alpha$-amylase: $\alpha$-glucosidase $=120: 80 \mathrm{U} / \mathrm{mL}$ ). The reaction took place under $37^{\circ} \mathrm{C}$ for $240 \mathrm{~min}$ with constant stirring ( $300 \mathrm{rpm}$ ). During the reaction, $500 \mu \mathrm{L}$ of the reaction solution was removed and terminated using ethyl alcohol at 30, $60,90,120,180$ and $240 \mathrm{~min}$. The supernatant was collected after centrifugation, and the glucose content was determined using the GOPOD method.

\subsection{Effects of FPE and BPE on Postprandial Glucose in Mice}

The effects of FPE and BPE on postprandial glucose in ICR mice were investigated according to a previous study [2]. Five-week-old male ICR mice were kept in 12-h day /night cycles and fed a standard chow diet for 1-week acclimatization. Overnight-fasted mice were administrated with maltose $(2 \mathrm{~g} / \mathrm{kg}$ ) and treatment solution (PBS, $25 \mathrm{mg} / \mathrm{kg}$ FPE, $50 \mathrm{mg} / \mathrm{kg}$ FPE, $25 \mathrm{mg} / \mathrm{kg}$ BPE, $50 \mathrm{mg} / \mathrm{kg}$ BPE, $20 \mathrm{mg} / \mathrm{kg}$ acarbose dissolved in PBS) by oral gavage, and then blood glucose was recorded with a glucose meter (Roche Diagnostics, Shanghai, China) at 0, 30, 60, 90 and $120 \mathrm{~min}$. All animal experimental procedures completely adhered to the Guidelines for Care and Use of Laboratory Animals of Shidong Hospital, Yangpu District, Shanghai, China and were approved by the Animal Ethics Committee of Shidong Hospital, Yangpu District, Shanghai, China.

\subsection{Statistical Analysis}

Results are presented as the mean \pm standard deviation (SD) for at least three replicates for each sample. Statistical analyses were performed using the SPSS program, version 17.0 (SPSS Inc., Chicago, IL, USA, 2009). Data were analyzed by ANOVA and significant differences were set at $p<0.05, p<0.01$ and $p<0.001$.

\section{Results}

\subsection{TPC, TFC and Antioxidant Activities of FPE and BPE}

The TPC and TFC of FPE and BPE are shown in Figure 1. The results of the FolinCiocalteu assay showed that the TPC of FPE and BPE were $1.710 \pm 0.031 \mathrm{mg} \mathrm{GAE} / \mathrm{g}$ and $4.717 \pm 0.085 \mathrm{mg}$ GAE $/ \mathrm{g}$, respectively. The TFC of FPE and BPE were $1.272 \pm 0.230 \mathrm{mg}$ $\mathrm{RE} / \mathrm{g}$ and $1.721 \pm 0.205 \mathrm{mg} \mathrm{RE} / \mathrm{g}$, respectively. Previous studies reported that the TPC of darker colored quinoa seeds was higher than that of white quinoa seeds $[10,15]$. Tang et al. compared the TPC and TFC in quinoa seeds with different colors and their results showed that the TPC of red quinoa seeds (about $4.3 \mathrm{mg} \mathrm{GAE} / \mathrm{g}$ ) was higher than that of white quinoa seeds (about $2.1 \mathrm{mg} \mathrm{GAE} / \mathrm{g}$ ) [15]. Furthermore, our results also showed that the 
TPC and TFC of BPE were significantly higher than those in FPE $(p<0.05)$, which was in consistency with some previous findings that the content of bound polyphenols was largely distributed in cereal grains, such as rice $(\sim 62 \%)$, wheat $(\sim 75 \%)$, corn $(\sim 85 \%)$, etc. [16].

(A)

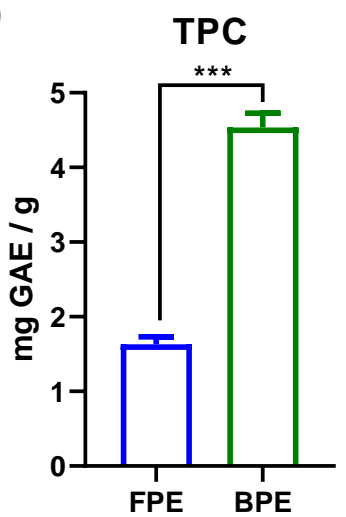

(B)

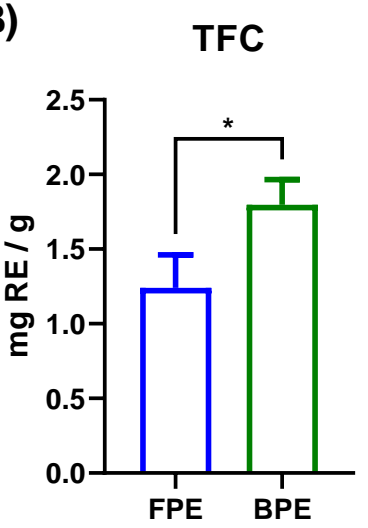

(C)

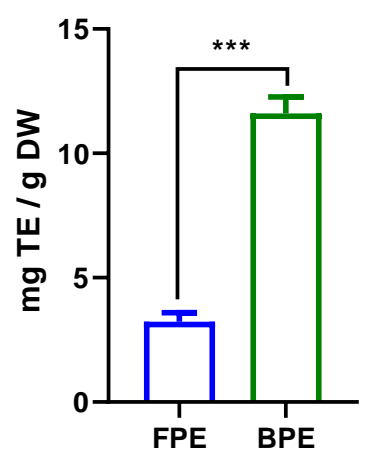

(D)

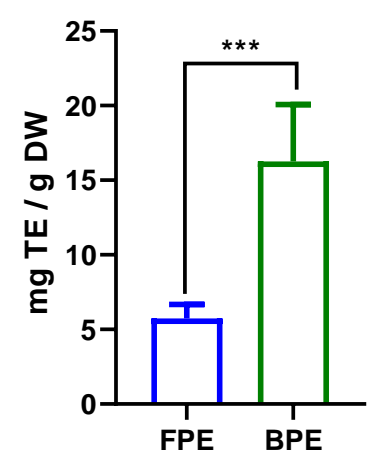

Figure 1. Total polyphenols content (A), total flavonoids content (B), antioxidant activities determined by DPPH (C) and ABTS assays (D) of FPE and BPE. Results are representative of three independent experiments and are expressed as mean $\pm \mathrm{SD} .\left({ }^{*}\right)\left({ }^{* * *}\right) p<0.05,0.001$, two-tailed Student's $t$-test.

The chemical antioxidant activities of FPE and BPE were evaluated by the DPPH and ABTS assays. Both the DPPH and ABTS values of BPE (11.601 $\pm 0.669 \mathrm{mg}$ TE/g DW, $16.251 \pm 3.824 \mathrm{mg}$ TE/g DW) were significantly higher than those of FPE $(3.231 \pm 0.361 \mathrm{mg}$ $\mathrm{TE} / \mathrm{g}$ DW, $5.732 \pm 0.940 \mathrm{mg} \mathrm{TE} / \mathrm{g} \mathrm{DW})$, which were in positive correlation with the TPC and TFC values. DPPH as a free radical has been widely used to evaluate the reducing molecules. ABTS is also frequently used in the food industry to determine the antioxidant activities of foods [17]. In comparison with cereal-based foods, both FPE and BPE exhibited stronger antioxidant activities [18]. Previous studies have shown that polyphenols are efficient hydrogen donors and electron transfer agents, which is in line with the principle of the DPPH and ABTS assays [19].

\subsection{Components of FPE and BPE}

The components of FPE and BPE were further analyzed via HPLC-MS (Figure 2). Table 1 shows the identification and quantification of the major peaks presented in Figure 2, with their retention times, mass spectral data and contents. As presented, a total of 13 polyphenols were identified, while the components of FPE and BPE varied a lot. Based on the mass spectrum and the comparison with commercial standards, the major phenolic components of FPE were 2-hydroxybenzoic acid, vanillin, caffeic acid, gallic acid and 3,4-dihydroxy-benzoic acid. These components are commonly found in fruits, vegetables and cereal grains, as previously reported [20]. Alkaline and acid treatment released a 
considerable amount of bound polyphenols from red quinoa. Five types of phenolic acid (3,4-dihydroxy-benzoic acid, vanillic acid, chlorogenic acid, p-coumaric acid and ferulic acid), two types of flavan-3-ols (catechin and epicatechin), one type of flavonoid (quercetin) and one type of phenolic glycoside (ferulic acid 4-glucoside) were identified in BPE. Among them, ferulic acid, ferulic acid 4-glucoside and quercetin contributed to a large part of BPE, which was also in consistency with some previous studies. They revealed that ferulic acid and its derivatives were the most common components of bound polyphenols from some major cereal grains, such as rice, wheat, barley, sorghum, etc. [6].

(A)

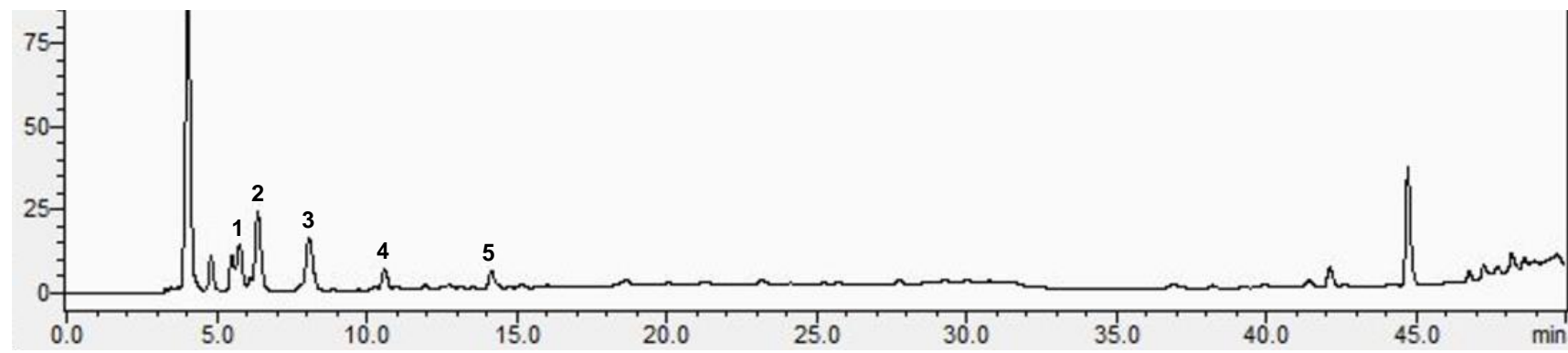

(B)

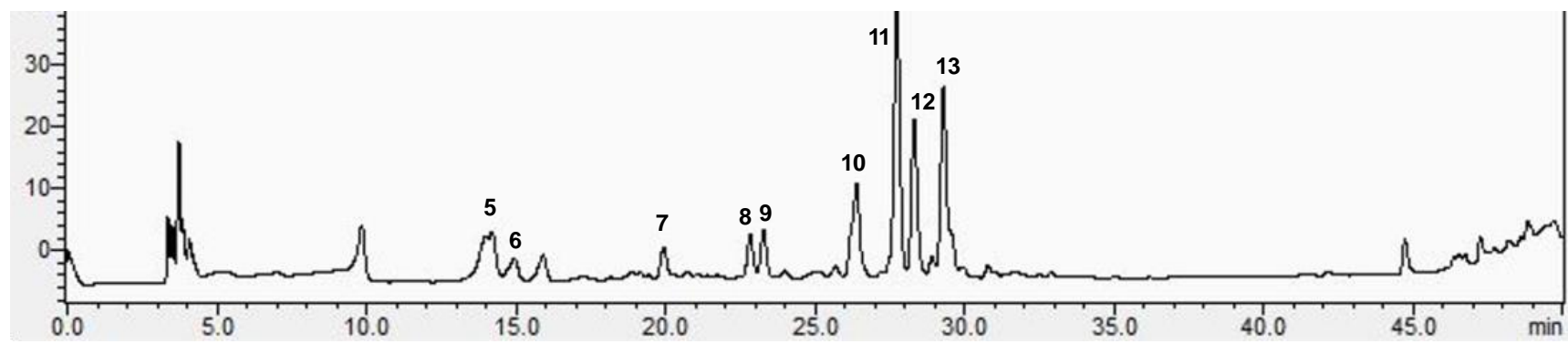

Figure 2. HPLC chromatogram of FPE (A) and BPE (B) from red quinoa. Peak 1: 2-hydroxybenzoic acid (tentatively identified); peak 2: vanillin; peak 3: caffeic acid; peak 4: gallic acid; peak 5: 3,4dihydroxy-benzoic acid; peak 6: vanillic acid; peak 7: catechin; peak 8: chlorogenic acid; peak 9: epicatechin; peak 10: p-Coumaric acid; peak 11: ferulic acid; peak 12: ferulic acid 4-glucoside (tentatively identified); peak 13: quercetin.

Table 1. Components of FPE and BPE from red quinoa.

\begin{tabular}{|c|c|c|c|c|c|c|}
\hline \multirow{2}{*}{ Peak } & \multirow{2}{*}{$\begin{array}{l}\text { Retention } \\
\text { Time (min) }\end{array}$} & \multirow{2}{*}{ Formula } & \multirow{2}{*}[\mathbf{M}-\mathrm{H}]{$^{-}(m / z)$} & \multirow{2}{*}{ Identification } & \multicolumn{2}{|c|}{ Content (mg/kg) } \\
\hline & & & & & FPE & BPE \\
\hline 1 & 5.84 & $\mathrm{C}_{7} \mathrm{H}_{6} \mathrm{O}_{3}$ & 137.03 & 2-hydroxybenzoic acid * & $4.927 \pm 1.023$ & ND \\
\hline 2 & 6.22 & $\mathrm{C}_{8} \mathrm{H}_{8} \mathrm{O}_{3}$ & 151.04 & Vanillin & $3.170 \pm 0.882$ & ND \\
\hline 3 & 8.04 & $\mathrm{C}_{9} \mathrm{H}_{8} \mathrm{O}_{4}$ & 179.04 & Caffeic acid & $2.388 \pm 0.673$ & ND \\
\hline 4 & 10.84 & $\mathrm{C}_{7} \mathrm{H}_{6} \mathrm{O}_{5}$ & 169.01 & Gallic acid & $2.614 \pm 0.541$ & ND \\
\hline 5 & 14.52 & $\mathrm{C}_{7} \mathrm{H}_{6} \mathrm{O}_{4}$ & 153.02 & 3,4-dihydroxy-benzoic acid & $2.774 \pm 0.696$ & $4.866 \pm 0.334$ \\
\hline 6 & 15.98 & $\mathrm{C}_{8} \mathrm{H}_{8} \mathrm{O}_{4}$ & 167.04 & Vanillic acid & ND & $2.615 \pm 0.272$ \\
\hline 7 & 19.98 & $\mathrm{C}_{15} \mathrm{H}_{14} \mathrm{O}_{6}$ & 289.07 & Catechin & ND & $2.788 \pm 0.468$ \\
\hline 8 & 22.76 & $\mathrm{C}_{16} \mathrm{H}_{18} \mathrm{O}_{9}$ & 353.09 & Chlorogenic acid & ND & $3.387 \pm 0.668$ \\
\hline 9 & 23.22 & $\mathrm{C}_{15} \mathrm{H}_{14} \mathrm{O}_{6}$ & 289.07 & Epicatechin & ND & $3.723 \pm 0.334$ \\
\hline 10 & 26.46 & $\mathrm{C}_{9} \mathrm{H}_{8} \mathrm{O}_{3}$ & 163.04 & $\mathrm{p}$-Coumaric acid & ND & $9.753 \pm 0.268$ \\
\hline 11 & 27.66 & $\mathrm{C}_{10} \mathrm{H}_{10} \mathrm{O}_{4}$ & 193.05 & Ferulic acid & ND & $20.938 \pm 3.866$ \\
\hline 12 & 28.44 & $\mathrm{C}_{16} \mathrm{H}_{20} \mathrm{O}_{9}$ & 355.02 & Ferulic acid 4-glucoside * & ND & $11.794 \pm 1.225$ \\
\hline 13 & 29.32 & $\mathrm{C}_{15} \mathrm{H}_{10} \mathrm{O}_{7}$ & 301.04 & Quercetin & ND & $18.048 \pm 1.236$ \\
\hline
\end{tabular}

* Peak 1 was tentatively identified as 2-hydroxybenzoic acid and was quantified as gallic acid equivalent. Peak 12 was tentatively identified as ferulic acid 4-glucoside and was quantified as ferulic acid equivalent. Values are expressed as $\mathrm{mg} / \mathrm{kg}$ quinoa (mean $\pm \mathrm{SD})(n=3)$. 


\subsection{Inhibitory Effects and Mechanism of FPE and BPE against $\alpha$-Glucosidase}

$\alpha$-glucosidase, located in the brush border of the small intestine, hydrolyzes terminal non-reducing $(1 \rightarrow 4)$-linked $\alpha$-glucose residues to release a single $\alpha$-glucose, which leads to an increase in blood glucose levels. The inhibitory effects of FPE and BPE were compared (Figure 3A,B). Both FPE and BPE inhibited the activity of $\alpha$-glucosidase in a dose-dependent manner. The $\mathrm{IC}_{50}$ values of FPE and $\mathrm{BPE}$ were $13.013 \pm 0.196 \mathrm{mg} / \mathrm{mL}$ and $10.295 \pm 0.223 \mathrm{mg} / \mathrm{mL}$, respectively. The $\mathrm{IC}_{50}$ value of BPE was lower than of FPE, indicating that the inhibitory effect of BPE on $\alpha$-glucosidase was stronger than that of FPE. Both FPE and BPE exhibited higher $\alpha$-glucosidase inhibitory activity than polyphenols from some other grains, such as corn and barley [21].

Reversible inhibitors can be classified into competitive, non-competitive, uncompetitive (or anti-competitive) and mixed types based on their interactions with the enzyme, which directly affect the values of $\mathrm{Km}$ and Vmax. Competitive inhibitors directly compete with the substrate to bind with the active site of the enzyme, while non-competitive inhibitors do not compete with the substrate and bind to the allosteric site of the enzyme instead. Uncompetitive inhibitors bind to the enzyme-substrate complex away from the active site of the enzyme, while mixed inhibitors bind to either the enzyme away from its active site or the enzyme-substrate complex [22]. The inhibition mode of $\alpha$-glucosidase was determined from the Lineweaver-Burk plot, and the enzyme kinetic parameters following $\alpha$-glucosidase inhibition with FPE and BPE are shown in Table 2. Figure 3 C shows that the $x$-intercept was almost unchanged with a reduced Vmax value after adding FPE, which indicated that FPE inhibited $\alpha$-glucosidase in a non-competitive mode. On the other hand, Figure 3D shows that after adding BPE, both the $\mathrm{Km}$ and the Vmax value decreased with two equations almost parallel to each other, indicating that BPE inhibited $\alpha$-glucosidase in an uncompetitive mode. The components of FPE varied a lot from those of BPE, and this might have contributed to their different inhibition modes.

(A)

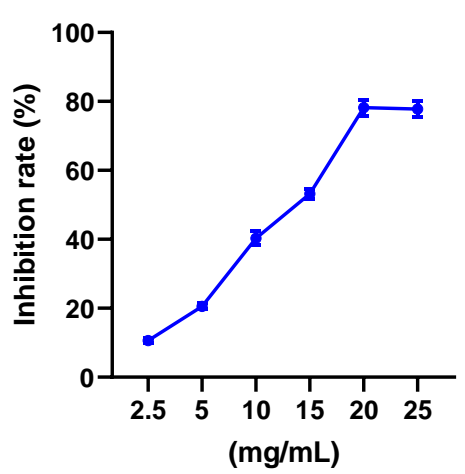

(C)

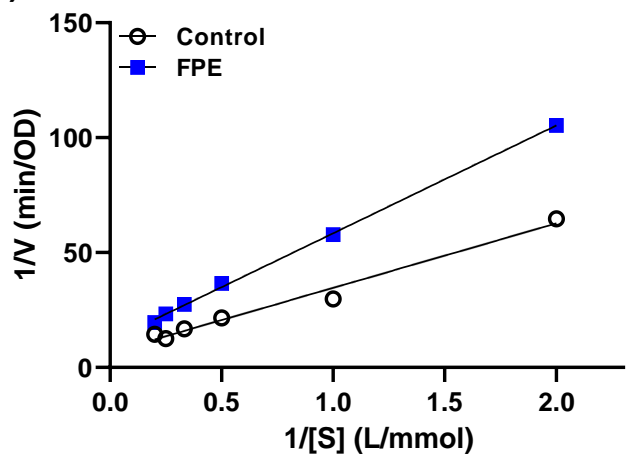

(B)

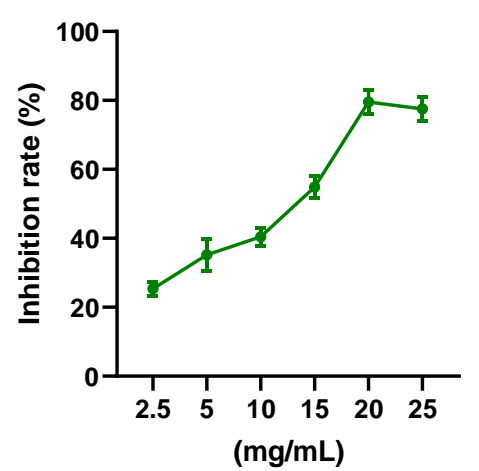

(D)

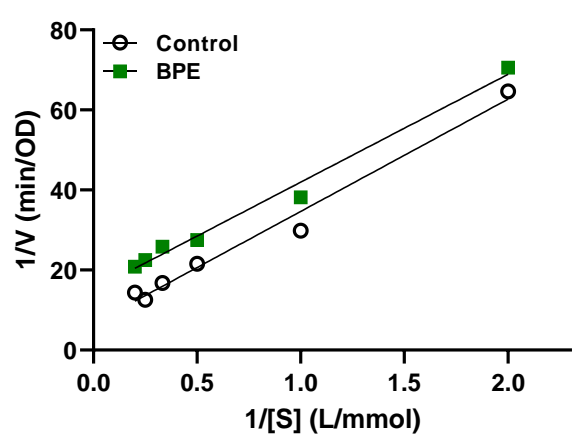

Figure 3. Inhibitory effects of FPE and BPE against $\alpha$-glucosidase. Inhibition curve of FPE (A) and BPE (B) on $\alpha$-glucosidase. Lineweaver-Burk plots of $\alpha$-glucosidase inhibited by FPE (C) and BPE (D). 
Table 2. Enzyme kinetic parameters following $\alpha$-glucosidase inhibition with FPE and BPE.

\begin{tabular}{ccccc}
\hline Samples & $\begin{array}{c}\text { Double } \\
\text { Reciprocal Equation }\end{array}$ & $\boldsymbol{K}_{m}$ (mmol/L) & $\boldsymbol{V}_{\text {max }}$ (OD/min) & $\mathbf{R}^{\mathbf{2}}$ \\
\hline No inhibitor & $\mathrm{y}=28.046 \mathrm{x}+6.602$ & 4.248 & 0.151 & 0.9821 \\
FPE $(20 \mathrm{mg} / \mathrm{mL})$ & $\mathrm{y}=46.893 \mathrm{x}+11.507$ & 4.075 & 0.087 & 0.9991 \\
BPE $(20 \mathrm{mg} / \mathrm{mL})$ & $\mathrm{y}=26.946 \mathrm{x}+15.011$ & 1.795 & 0.067 & 0.9874 \\
\hline
\end{tabular}

\subsection{Effects of FPE and BPE on the Digestion of Rice Starch In Vitro}

The effects of FPE and BPE on the digestion of rice starch in vitro are shown in Figure 4. The digestion curves showed an exponential growth shape with a rapid digestion stage (0-60 $\mathrm{min})$, followed by a much slower digestion phase afterwards until reaching the digestion plateau. At $240 \mathrm{~min}$, the starch-digestion ratio of the control group reached $79.51 \%$. The addition of FPE and BPE inhibited the starch digestion process to some extent. The starch digestion ratios were $72.74 \%$ and $70.28 \%$ at $240 \mathrm{~min}$ after the addition of FPE and BPE at $10 \mathrm{mg} / \mathrm{mL}$, respectively, showing significant differences compared with the control $(p<0.05)$. In consistency with previous studies, BPE with the highest level of TPC, TFC and various components of polyphenols prevailed over FPE in terms of inhibiting starch digestion.

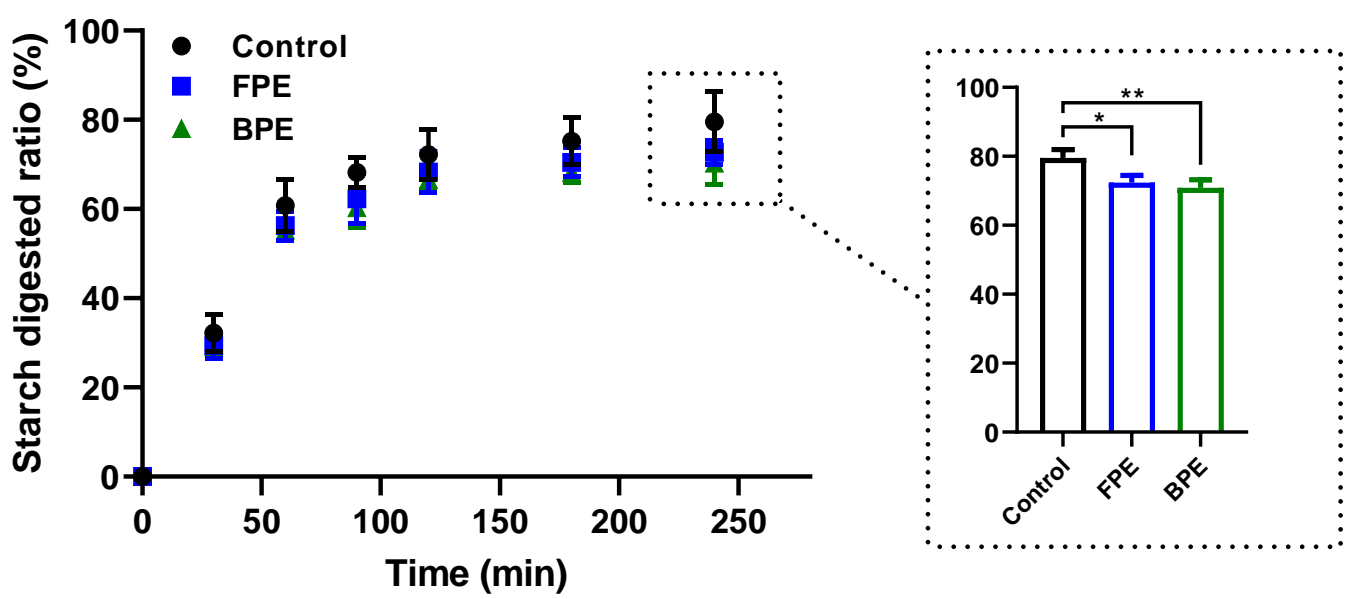

Figure 4. Effects of FPE and BPE on the digestion of rice starch in vitro. Results are expressed as mean $\pm \mathrm{SD}(n=3) .\left(^{*}\right)(* *) p<0.05,0.01$, compared with the control. Multiple comparisons were performed by one-way analysis of variance (ANOVA) followed by Tukey's test.

\subsection{Effects of FPE and BPE on Postprandial Blood Glucose Levels In Vivo}

To further explore the inhibitory effects of FPE and BPE on $\alpha$-glucosidase in vivo, an oral maltose tolerance test was performed in a normal ICR mice model. Concentrations of $2 \mathrm{~g} / \mathrm{kg}$ of maltose were administered to the mice. In addition, $20 \mathrm{mg} / \mathrm{kg}$ of acarbose was used as a positive control. As presented in Figure 5A, the blood glucose level of all mice increased quickly in 30 min after maltose administration (about $15.25 \mathrm{mM}$ ), and gradually decreased afterwards. The rapid turbulence of blood glucose was improved by the administration of acarbose, FPE and BPE. At $30 \mathrm{~min}$, the blood glucose levels of the maltose+acarbose group $(20 \mathrm{mg} / \mathrm{kg})$, the maltose+FPE group $(50 \mathrm{mg} / \mathrm{kg})$ and the maltose+BPE group ( $50 \mathrm{mg} / \mathrm{kg}$ ) were $6.83 \mathrm{mM}, 9.80 \mathrm{mM}$ and $9.74 \mathrm{mM}$, respectively. The Area Under the Curve (AUC) was derived from the oral maltose tolerance test (Figure 5B). Administration of acarbose and BPE significantly reduced the AUC of mice $(p<0.05)$. Compared with the AUC of the maltose group, a $25.8 \%$ of reduction was observed in the maltose+acarbose group, and a $21.4 \%$ of reduction was observed in the maltose+BPE group $(50 \mathrm{mg} / \mathrm{kg})$. The suppressive effect of BPE at $50 \mathrm{mg} / \mathrm{kg}$ on postprandial hyperglycemia was comparable to that of acarbose at $20 \mathrm{mg} / \mathrm{kg}$, indicating that BPE can be considered as a natural $\alpha$-glucosidase inhibitor. 
(A)

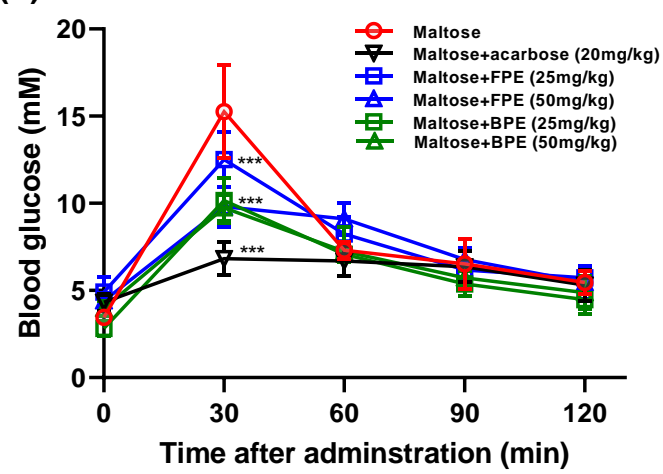

(B)

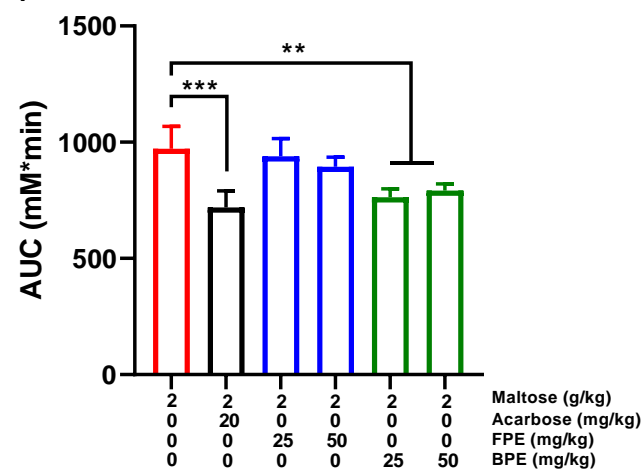

Figure 5. Effects of FPE and BPE on postprandial blood glucose levels in vivo. (A) Blood glucose levels after oral administration of maltose and acarbose, FPE and BPE $(n=5)$. (B) Area Under the Curve (AUC) after oral administration of maltose and acarbose, FPE and BPE for $2 \mathrm{~h}$. Results are expressed as mean $\pm \mathrm{SD}(n=5) .\left(^{* *}\right)\left({ }^{* * *}\right) p<0.01,0.001$, compared with the maltose group. Multiple comparisons were performed by one-way analysis of variance (ANOVA) followed by Tukey's test.

\section{Discussion}

T2DM has been a rapidly growing health problem in recent years. An estimated 850 billion USD was spent globally on the treatment and health interventions for diabetes in 2017 [23]. This number is expected to rise to 958 billion USD by 2045 [24]. Many clinical drugs have been invented to treat or manage T2DM by (a) stimulating the secretion of insulin and (b) interrupting or delaying the digestion of dietary starch to reduce the rate of blood sugar absorption from the small intestine [25]. Aiming at (b), acarbose and miglitol, acting as $\alpha$-glucosidase inhibitors, were approved by the FDA to manage postprandial glucose rises. $\alpha$-glucosidase is secreted in the small intestine and is found in the luminal surface of enterocytes. $\alpha$-glucosidase is a key enzyme catalyzing the hydrolytic cleavage of disaccharides (maltose and sucrose) into monosaccharides (glucose and fructose). Thus, inhibiting the activity of $\alpha$-glucosidase reduces the increasing of blood sugar and alleviates postprandial hyperglycemia [25]. However, side effects brought about by these drugs and high expenditure drive people to seek out effective plant-derived compounds serving as $\alpha$-glucosidase inhibitors.

Diets rich in polyphenols have been extensively studied in the past decade in terms of their effects on T2DM. A number of meta-analysis studies revealed that consuming polyphenol-enriched diets played a vital role in the prevention of T2DM, and this was found to be associated with lower risk of T2DM [26,27]. Some randomized controlled trails also revealed that the consumption of plant-derived polyphenols decreased fasting and post-prandial glucose and improved glucose metabolism in participants [28]. Polyphenols helped to manage T2DM in different ways, such as inhibiting digestive enzymes, regulating glucose metabolic pathways and modulating gut microbiota [29]. Similar to acarbose, some plant-derived polyphenols showed strong inhibitory effects on $\alpha$-glucosidase and thus reduced the rate of digestion of complex starches, oligo-, tri- and disaccharides into absorbable glucose [25]. In recent years, quinoa has attracted growing attention due to its rich nutrients and many health benefits [30]. Compared with fruits and vegetables, cereal grains contain a much higher content of bound polyphenols (about $60 \%$ ), which have always been neglected in terms of their activities and health benefits [6]. Our results exhibited that the content of BPE in red quinoa was about 2.7 times as much as that of FPE (Figure 1). Compared with FPE, BPE not only showed higher chemical antioxidant activities, as determined by the DPPH and ABTS assays, but also had stronger inhibitory effects on $\alpha$-glucosidase ( $\mathrm{IC}_{50}$ of $\mathrm{BPE}<\mathrm{IC}_{50}$ of FPE).

Compared with free polyphenols, studies on the enzyme-inhibitory activities of bound polyphenols were limited. Zheng et al. used acid/alkaline hydrolysis to extract bound polyphenols from mung bean skin and showed that it was mainly composed of caffeic 
acid and protocatechuic acid and could inhibit the activity of $\alpha$-glucosidase [31]. Yan et al. released non-extractable polyphenols of green tea by acid hydrolysis, and found that non-extractable polyphenols exhibited $\alpha$-glucosidase inhibitory effects in a noncompetitive manner, although such effects were weaker than those of extractable polyphenols of green tea [14]. Meanwhile, Dong et al. found that in vitro fermentation released bound polyphenols from carrot dietary fiber, which showed stronger antioxidant activity than before fermentation and exhibited $\alpha$-glucosidase inhibitory activity that was equivalent to that of acarbose [32]. Our results were in line with some previous findings that bound polyphenols showed stronger antioxidant and $\alpha$-glucosidase inhibitory activities than free polyphenols. Studying the activities of bound polyphenols still requires further efforts. Particularly, the comparison between free polyphenols and bound polyphenols in terms of their components and activities needs further exploration.

The composition of polyphenols might contribute to the differences between BPE and FPE regarding their antioxidant and enzyme-inhibitory effects. HPLC-MS analysis showed that hydroxybenzoic acids were the major components of FPE, while ferulic acid, ferulic acid 4-glucoside and quercetin were the major components of BPE (Figure 2, Table 1). These components exhibited strong antioxidant activities and inhibitory effects on enzymes as single compounds in previous reports [25]. Ferulic acid, as a major component of BPE, in particular, was reported to exert equivalent activity to acarbose [32]. The inhibitory mechanisms of polyphenols in $\alpha$-glucosidase might be due to the following reasons: (a) hydrogen bonds and hydrophobic forces are formed between polyphenols and the active sites of the enzyme [33]; (b) ferulic acid was reported to increase the $\alpha$-helix and decrease the $\beta$-sheet of $\alpha$-glucosidase and, thus, hamper the active site formation or prevent substrate binding to alter the activity of $\alpha$-glucosidase; (c) molecular docking analysis demonstrated that ferulic acid was mainly surrounded by the amino acid residues Asp215, Glu277, Gln279, Arg 315, Glu411, Tyr 158, Phe 159 and Phe178 of $\alpha$-glucosidase, and thus formed three hydrogen bonds (Asp215, Glu277, Tyr158) and three $\pi-\pi$ T-shaped (Phe158, Phe178, and Tyr 158) interactions. This further perturbed the protein structure of $\alpha$-glucosidase [34]. Furthermore, different components of FPE and BPE also induced their different inhibition modes on $\alpha$-glucosidase. The Lineweaver-Burk model indicated that FPE might bind to the allosteric site of $\alpha$-glucosidase (non-competitive mode), while BPE might bind to the $\alpha$-glucosidase-pNPG complex away from the active site of $\alpha$-glucosidase instead (uncompetitive mode). Interactions between one polyphenol and the enzyme or one polyphenol and another comprehensively affect the binding sites to the enzyme or the enzyme-substrate complex.

To further evaluate the outcome of the inhibitory effects of FPE and BPE on $\alpha$ glucosidase, an in vitro starch digestion assay (Figure 4) and an in vivo postprandial blood glucose test (Figure 5) were carried out. The in vitro starch digestion assay showed that both FPE and BPE inhibited the process of starch digestion, and BPE delayed starch digestion to a larger extent compared with FPE. Furthermore, the results from the in vivo postprandial blood glucose test were in line with the in vitro starch digestion assay, showing that BPE significantly reduced the AUC for postprandial blood glucose compared with the maltose group. The effect of BPE at a higher dose $(50 \mathrm{mg} / \mathrm{kg})$ was comparable to that of acarbose $(20 \mathrm{mg} / \mathrm{kg})$. By inhibiting the activity of $\alpha$-glucosidase in an uncompetitive mode, BPE effectively inhibited starch digestion in vitro and reduced the postprandial glucose increase in vivo.

\section{Conclusions and Future Perspectives}

In conclusion, the components, antioxidant activities, $\alpha$-glucosidase inhibitory activity and mechanism, inhibition in starch digestion and in vivo postprandial glucose of FPE and BPE were investigated and compared in the present study. Alkaline and acid treatment released a large amount of bound polyphenols from red quinoa, and BPE showed higher levels of TPC and TFC than those of FPE. The HPLC-MS analysis revealed that the components between FPE and BPE varied greatly. Mainly composed of ferulic acid 
and its derivates, BPE showed stronger chemical antioxidant activities and $\alpha$-glucosidase inhibitory activity. The Lineweaver-Burk model showed that FPE and BPE inhibited $\alpha$ glucosidase activity in a non-competitive mode and an uncompetitive mode, respectively. By inhibiting $\alpha$-glucosidase, BPE delayed starch digestion and suppressed postprandial hyperglycemia effectively. Bound polyphenols have been overlooked regarding their activities and application for a long time. Cereals grains consumed as staple foods all over the world contain rich bound polyphenols awaiting further investigation. Given that T2DM is prevailing around the world, exploiting functional components from cereal grains (staple foods) is necessary to manage T2DM. Our results demonstrate that BPE as a functional food has the potential to control postprandial glucose and, thus, is worth further investigation.

Author Contributions: Y.Z.: writing, review, editing, funding acquisition. B.B.: investigation, data acquisition. Y.Y.: investigation, data acquisition. J.L.: data acquisition. X.G.: conceptualization, funding acquisition. All authors have read and agreed to the published version of the manuscript.

Funding: This research was funded by the Shanghai Agriculture Applied Technology Development Program, China (2021-02-08-00-12-F00780), the Shanghai Sailing Program (21YF1431800) and the Capacity-Building Project of Local Universities of SSTC (20060502100).

Institutional Review Board Statement: The protocol of this study was approved by the Animal Ethics Committee of Shidong Hospital, Yangpu District, Shanghai, China (2021-020-01).

Informed Consent Statement: Exclude this statement.

Data Availability Statement: Exclude this statement.

Acknowledgments: We express thanks for the support received from the Shanghai Agriculture Applied Technology Development Program, China, the Shanghai Sailing Program and the CapacityBuilding Project of Local Universities of SSTC.

Conflicts of Interest: The authors declare that they have no known competing financial interests or personal relationships that could have appeared to influence the work reported in this paper.

\section{References}

1. Sun, C.; Liu, Y.; Zhan, L.; Rayat, G.R.; Xiao, J.; Jiang, H.; Li, X.; Chen, K. Anti-diabetic effects of natural antioxidants from fruits. Trends Food Sci. Technol. 2020, 117, 3-14. [CrossRef]

2. Xu, Y.; Xie, L.H.; Xie, J.H.; Liu, Y.; Chen, W. Pelargonidin-3-O-rutinoside as a novel alpha-glucosidase inhibitor for improving postprandial hyperglycemia. Chem. Commun. 2019, 55, 39-42. [CrossRef] [PubMed]

3. Choi, C.W.; Choi, Y.H.; Cha, M.R.; Yoo, D.S.; Kim, Y.S.; Yon, G.H.; Hong, K.S.; Kim, Y.H.; Ryu, S.Y. Yeast alpha-Glucosidase Inhibition by Isoflavones from Plants of Leguminosae as an in Vitro Alternative to Acarbose. J. Agric. Food Chem. 2010, 58, 9988-9993. [CrossRef] [PubMed]

4. Sun, L.J.; Gidley, M.J.; Warren, F.J. The mechanism of interactions between tea polyphenols and porcine pancreatic alpha-amylase: Analysis by inhibition kinetics, fluorescence quenching, differential scanning calorimetry and isothermal titration calorimetry. Mol. Nutr. Food Res. 2017, 61, 1700324. [CrossRef]

5. Gong, L.; Feng, D.; Wang, T.; Ren, Y.; Liu, Y.; Wang, J. Inhibitors of alpha-amylase and alpha-glucosidase: Potential linkage for whole cereal foods on prevention of hyperglycemia. Food Sci. Nutr. 2020, 8, 6320-6337. [CrossRef]

6. Zhang, B.; Zhang, Y.; Li, H.; Deng, Z.; Tsao, R. A review on insoluble-bound phenolics in plant-based food matrix and their contribution to human health with future perspectives. Trends Food Sci. Technol. 2020, 105, 347-362. [CrossRef]

7. Zhang, X.W.; Dong, L.H.; Jia, X.C.; Liu, L.; Chi, J.W.; Huang, F.; Ma, Q.; Zhang, M.W.; Zhang, R.F. Bound Phenolics Ensure the Antihyperglycemic Effect of Rice Bran Dietary Fiber in db/db Mice via Activating the Insulin Signaling Pathway in Skeletal Muscle and Altering Gut Microbiota. J. Agric. Food Chem. 2020, 68, 4387-4398. [CrossRef]

8. Filho, A.M.; Pirozi, M.R.; Borges, J.T.; Sant'Ana, H.M.P.; Chaves, J.B.; Coimbra, J.S. Quinoa: Nutritional, functional, and antinutritional aspects. Crit. Rev. Food Sci. Nutr. 2017, 57, 1618-1630. [CrossRef]

9. Pellegrini, M.; Lucas-Gonzales, R.; Ricci, A.; Fontecha, J.; Fernández-López, J.; Pérez-Álvarez, J.A.; Viuda-Martos, M. Chemical, fatty acid, polyphenolic profile, techno-functional and antioxidant properties of flours obtained from quinoa (Chenopodium quinoa Willd) seeds. Ind. Crops Prod. 2018, 111, 38-46. [CrossRef]

10. Tang, Y.; Zhang, B.; Li, X.H.; Chen, P.X.; Zhang, H.; Liu, R.H.; Tsao, R. Bound Phenolics of Quinoa Seeds Released by Acid, Alkaline, and Enzymatic Treatments and Their Antioxidant and alpha-Glucosidase and Pancreatic Lipase Inhibitory Effects. J. Agric. Food Chem. 2016, 64, 1712-1719. [CrossRef]

11. Zhao, P.; Duan, L.; Guo, L.; Dou, L.L.; Dong, X.; Zhou, P.; Li, P.; Liu, E.H. Chemical and biological comparison of the fruit extracts of Citrus wilsonii Tanaka and Citrus medica L. Food Chem. 2015, 173, 54-60. [CrossRef] [PubMed] 
12. Bao, J.S.; Cai, Y.Z.; Sun, M.; Wang, G.Y.; Corke, H. Anthocyanins, flavonols, and free radical scavenging activity of Chinese bayberry (Myrica rubra) extracts and their color properties and stability. J. Agric. Food Chem. 2005, 53, 2327-2332. [CrossRef] [PubMed]

13. Wang, M.T.; Chen, J.C.; Ye, X.Q.; Liu, D.H. In vitro inhibitory effects of Chinese bayberry (Myrica rubra Sieb. et Zucc.) leaves proanthocyanidins on pancreatic alpha-amylase and their interaction. Bioorg. Chem. 2020, 101, 104029. [CrossRef]

14. Yan, S.S.; Shao, H.J.; Zhou, Z.H.; Wang, Q.; Zhao, L.H.; Yang, X.B. Non-extractable polyphenols of green tea and their antioxidant, anti-alpha-glucosidase capacity, and release during in vitro digestion. J. Funct. Foods 2018, 42, 129-136. [CrossRef]

15. Tang, Y.; Li, X.H.; Zhang, B.; Chen, P.X.; Liu, R.H.; Tsao, R. Characterisation of phenolics, betanins and antioxidant activities in seeds of three Chenopodium quinoa Willd. Genotypes. Food Chem. 2015, 166, 380-388. [CrossRef]

16. Acosta-Estrada, B.A.; Gutierrez-Uribe, J.A.; Serna-Saldivar, S.O. Bound phenolics in foods, a review. Food Chem. 2014, 152, 46-55. [CrossRef] [PubMed]

17. Zhang, Y.; Zhou, X.Z.; Tao, W.Y.; Li, L.Q.; Wei, C.Y.; Duan, J.E.; Chen, S.G.; Ye, X.Q. Antioxidant and antiproliferative activities of proanthocyanidins from Chinese bayberry (Myrica rubra Sieb. et Zucc.) leaves. J. Funct. Foods 2016, 27, 645-654. [CrossRef]

18. Rocchetti, G.; Giuberti, G.; Lucini, L. Gluten-free cereal-based food products: The potential of metabolomics to investigate changes in phenolics profile and their in vitro bioaccessibility. Curr. Opin. Food Sci. 2018, 22, 1-8. [CrossRef]

19. Aron, P.M.; Kennedy, J.A. Flavan-3-ols: Nature, occurrence and biological activity. Mol. Nutr. Food Res. 2008, 52, 79-104. [CrossRef]

20. Nayak, B.; Liu, R.H.; Tang, J.M. Effect of Processing on Phenolic Antioxidants of Fruits, Vegetables, and Grains-A Review. Crit. Rev. Food Sci. Nutr. 2015, 55, 887-918. [CrossRef]

21. Yao, Y.; Sang, W.; Zhou, M.; Ren, G. Antioxidant and alpha-glucosidase inhibitory activity of colored grains in China. J. Agric. Food Chem. 2010, 58, 770-774. [CrossRef] [PubMed]

22. Pinaffi, A.C.D.; Sampaio, G.R.; Soares, M.J.; Shahidi, F.; de Camargo, A.C.; Torres, E.A.F.S. Insoluble-Bound Polyphenols Released from Guarana Powder: Inhibition of Alpha-Glucosidase and Proanthocyanidin Profile. Molecules 2020, 25, 679. [CrossRef] [PubMed]

23. NCD Risk Factor Collaboration (NCD-RisC). Worldwide trends in diabetes since 1980: A pooled analysis of 751 population-based studies with 4.4 million participants. Lancet 2016, 387, 1513-1530. [CrossRef]

24. Cho, N.H.; Shaw, J.E.; Karuranga, S.; Huang, Y.; Fernandes, J.D.D.; Ohlrogge, A.W.; Malanda, B. IDF Diabetes Atlas: Global estimates of diabetes prevalence for 2017 and projections for 2045. Diabetes Res. Clin. Pract. 2018, 138, 271-281. [CrossRef] [PubMed]

25. Papoutsis, K.; Zhang, J.Y.; Bowyer, M.C.; Brunton, N.; Gibney, E.R.; Lyng, J. Fruit, vegetables, and mushrooms for the preparation of extracts with alpha-amylase and alpha-glucosidase inhibition properties: A review. Food Chem. 2021, 338, 128119. [CrossRef] [PubMed]

26. Liu, Y.J.; Zhan, J.; Liu, X.L.; Wang, Y.; Ji, J.; He, Q.Q. Dietary flavonoids intake and risk of type 2 diabetes: A meta-analysis of prospective cohort studies. Clin. Nutr. 2014, 33, 59-63. [CrossRef]

27. Rienks, J.; Barbaresko, J.; Oluwagbemigun, K.; Schmid, M.; Nothlings, U. Polyphenol exposure and risk of type 2 diabetes: Dose-response meta-analyses and systematic review of prospective cohort studies. Am. J. Clin. Nutr. 2018, 108, 49-61. [CrossRef]

28. da Porto, A.; Cavarape, A.; Colussi, G.; Casarsa, V.; Catena, C.; Sechi, L.A. Polyphenols Rich Diets and Risk of Type 2 Diabetes Nutrients 2021, 13, 1445. [CrossRef]

29. Wang, Y.; Alkhalidy, H.; Liu, D.M. The Emerging Role of Polyphenols in the Management of Type 2 Diabetes. Molecules 2021, 26, 703. [CrossRef]

30. Navruz-Varli, S.; Sanlier, N. Nutritional and health benefits of quinoa (Chenopodium quinoa Willd.). J. Cereal. Sci. 2016, 69, 371-376. [CrossRef]

31. Zheng, Y.; Liu, S.; Xie, J.; Chen, Y.; Dong, R.; Zhang, X.; Liu, S.; Xie, J.; Hu, X.; Yu, Q. Antioxidant, $\alpha$-amylase and $\alpha$-glucosidase inhibitory activities of bound polyphenols extracted from mung bean skin dietary fiber. LWT 2020, 132, 109943. [CrossRef]

32. Dong, R.H.; Liu, S.; Zheng, Y.T.; Zhang, X.J.; He, Z.C.; Wang, Z.P.; Wang, Y.Y.; Xie, J.H.; Chen, Y.; Yu, Q. Release and metabolism of bound polyphenols from carrot dietary fiber and their potential activity inin vitrodigestion and colonic fermentation. Food Funct. 2020, 11, 6652-6665. [CrossRef] [PubMed]

33. Miao, M.; Jiang, B.; Jiang, H.; Zhang, T.; Li, X.F. Interaction mechanism between green tea extract and human alpha-amylase for reducing starch digestion. Food Chem. 2015, 186, 20-25. [CrossRef]

34. Zheng, Y.; Tian, J.; Yang, W.; Chen, S.; Liu, D.; Fang, H.; Zhang, H.; Ye, X. Inhibition mechanism of ferulic acid against alpha-amylase and alpha-glucosidase. Food Chem. 2020, 317, 126346. [CrossRef] [PubMed] 